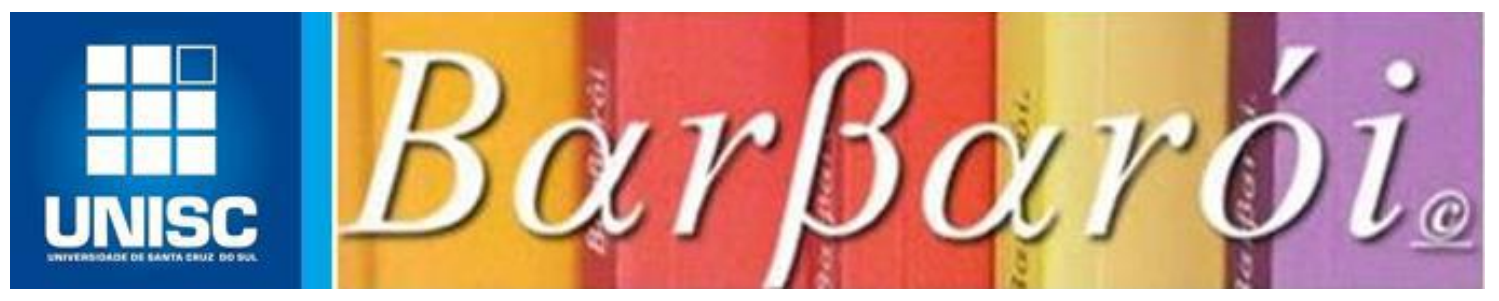

\title{
“MEU MUNDO INTERIOR - SENTIMENTOS": RELATO DE EXPERIÊNCIA DE ESTÁGIO EM PSICOLOGIA ESCOLAR/EDUCACIONAL
}

DOI: http://dx.doi.org/10.17058/barbaroi.v1i53.11490

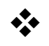 \\ Fernanda Brugnera \\ Faculdade Meridional - IMED - Brasil \\ Naiana Dapieve Patias \\ Universidade Federal de Santa Maria (UFSM)

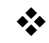

\section{Resumo}

A educação emocional pode ser uma das formas de atuação da psicologia escolar/educacional. Trata-se de uma possibilidade para prevenção de conflitos que auxilia crianças a reconhecer e manifestar, de maneira adequada, seus sentimentos. Este artigo descreve a experiência de estágio básico o qual foi realizado em uma escola privada de ensino fundamental de uma cidade do norte do Rio Grande do Sul. Após observações da demanda, foi construído o projeto de intervenção nomeado "Meu mundo interior - Sentimentos", o qual foi aplicado em três turmas do segundo ano do ensino fundamental. $\mathrm{O}$ mesmo foi realizado pela estagiária juntamente com a professora de cada turma, em um total de sete encontros de aproximadamente uma hora de duração cada. As crianças puderam reconhecer, verbalizar e expressar diversos sentimentos.

Palavras chaves: educação emocional; crianças; psicologia escolar.

\section{Introdução}

A psicologia escolar/educacional tem por objetivo colaborar, de forma ativa, no desenvolvimento da comunidade escolar. O profissional psicólogo escolar pode ajudar na eficácia do processo educacional, pois pode atuar de forma a prevenir e promover saúde em ambiente educacional (ANDRADA, 2005; PATIAS; ABAID, 2014). Desta forma, este profissional pode intervir, sobre diversos temas, em grupos com professores, pais, gestores, funcionários e alunos (DIAS; PATIAS; ABAID, 2014). 
De maneira preventiva, as intervenções podem ser realizadas com qualquer grupo escolar. No entanto, o trabalho com grupo de crianças sobre emoções tem sido indicado como uma importante estratégia diante da inabilidade de algumas crianças em lidar com mudanças da escola, por exemplo. Ainda, quando há o surgimento de conflitos entre crianças, entre crianças e adultos, a habilidade para identificar emoções pode prevenir problemas de relacionamento além de psicopatologias futuras (RODRIGUES, 2015). Desta forma, o objetivo maior em trabalhar com as emoções na escola é a prevenção, a fim de permitir que a criança possa criar uma barreira de proteção por meio de atitudes e habilidades, como a identificação e o controle de suas emoções, as quais serão aprendidas. Assim, o trabalho sobre as emoções pode prevenir o surgimento de problemas emocionais além de trazer benefícios aos relacionamentos interpessoais das crianças que dele participam (RODRIGUES, 2015).

Aliada à importância do trabalho com as emoções, o papel da escola é indiscutível, pois é neste local que surgem as primeiras relações das crianças com seus pares, sendo um contexto de grande importância ao desenvolvimento psicossocial desses indivíduos. Neste sentindo, a escola deve propiciar um espaço para que os alunos compartilhem suas emoções, dando a possibilidade de as crianças aprenderem a escutar os outros e também a si mesmas. De fato, todas as crianças devem ter a oportunidade de aprender a comunicar seus sentimentos, possibilitando a compreensão e empatia por parte dos colegas e, como consequência, podendo diminuir o sofrimento psicológico infantil (FRONER, 2008).

Diante disso, o presente artigo descreve uma experiência de estágio básico curricular da graduação em psicologia da primeira autora, supervisionada pela segunda autora. $\mathrm{O}$ estágio foi realizado em uma escola privada de ensino fundamental de uma cidade do norte do Rio Grande do Sul. Após observações da demanda, foi construído o projeto de intervenção nomeado "Meu mundo interior - Sentimentos", o qual foi aplicado em três turmas do segundo ano do ensino fundamental. Especificamente, o projeto desenvolvido teve como objetivo possibilitar um espaço de reflexão sobre os sentimentos e refletir sobre quais as melhores formas de expressá-los, incluindo o “perceber”, o “nomear”, o "verbalizar” e o “expressar” e o "comportamento" (RODRIGUES, 2015; 2016). 


\section{Método}

Baseada nos princípios da Educação Emocional Positiva (RODRIGUES, 2015; 2016) e nas ideias de Caminha e Caminha (2011), a presente intervenção foi realizada em contexto de Estágio Básico I e II curricular do curso de Psicologia de uma faculdade situada no norte do Estado do Rio Grande do Sul. O estágio foi realizado em uma escola privada da cidade entre fevereiro e novembro de 2017. Após as observações do contexto escolar, surgiu como demanda o trabalho sobre sentimentos com três turmas do segundo ano do Ensino Fundamental, com média de idade de 8 anos. Assim, foi construído um projeto de intervenção denominado "Meu mundo interior sentimentos". No projeto, foram utilizadas histórias, o Baralho das emoções, dinâmicas de grupos e materiais para desenhos e escrita (cola, papel, caneta, canetinhas, etc).

Para tanto, foram realizados sete encontros com cada uma das três turmas de segundo ano do ensino fundamental da escola. Os encontros ocorreram semanalmente, com duração aproximada de 1 hora, nos meses de setembro à outubro de 2017. Para cada encontro foram discutidos, em supervisão coletiva na instituição de ensino, sobre os objetivos e quais atividades seriam realizadas. Cada atividade foi adaptada de livros ou manuais de psicologia. Outras atividades foram criadas pela graduanda de Psicologia. Os encontros foram realizados pela estagiária de psicologia juntamente com as professoras das respectivas turmas. Os mesmos serão descritos de forma geral, não especificando as turmas em que foram realizadas, apenas as atividades de cada encontro.

\section{Resultados}

\section{O primeiro encontro: $O$ contrato, os sentimentos e para que eles servem}

No primeiro encontro foram realizadas as apresentações dos alunos e construído um "contrato" de trabalho, no qual foram desenvolvidos os objetivos e as regras a serem adotadas durante a execução do projeto. Após isso, as crianças foram questionadas sobre o que são, na sua concepção, os sentimentos. As respostas foram "são a nossa forma de expressar o que acontece com a gente" ou "são reações que o nosso coração dá para o que acontece com a gente". Seguido da pergunta foi explicado que ao longo da nossa vida passamos por diferentes situações e que, para cada uma delas, o nosso cérebro produz respostas, como a raiva, o medo, a alegria, etc., que são os nossos sentimentos. Para exemplificar, foi sugerida uma situação: "quando ganhamos um presente, por mais que o presente não nos agrade, ele significa que a pessoa que o comprou disponibilizou uma parte do seu tempo para pensar em nós e no que gostamos, e este esforço da pessoa em nos 
agradar deve ser considerado; então a pessoa nos entrega o presente e o nosso cérebro produz uma resposta, essa resposta é um sentimento, o sentimento que temos quando ganhamos um presente é a alegria".

Depois dessa explicação, os alunos receberam uma nova pergunta: "para que servem os sentimentos?". Dentre as várias respostas, uma delas foi “eles dão sentido para a nossa vida". Os alunos e a estagiária de psicologia puderam discutir sobre as respostas e, após isso, a estagiária explicou que os sentimentos dão significado para os objetos e situações que a vida nos apresenta. Como exemplo, os alunos foram convidados a imaginar a situação "um colar dado pela avó, pela qual a pessoa que o ganhou tem grande afeição. Então, toda vez que esta pessoa olha para o colar e lembra da avó, sente saudades e alegria e estes sentimentos atribuem um significado especial para aquele colar, que agora deixou de ser um colar qualquer."

Após isso, os alunos foram convidados a participar de uma atividade na qual deveriam pegar uma carta contendo algum sentimento e dar uma explicação do que sabem sobre o sentimento, se já o vivenciaram e, caso sentissem vontade, poderiam compartilhar alguma situação e quais estratégias utilizaram para "acalmar" o sentimento. Alguns alunos relataram que na tristeza "o coração dói, parece que se quebra quando estamos tristes". Como estratégia, falaram "podemos brincar, assistir à televisão, ou conversar com alguém quando estamos tristes”. Esta solução também foi apresentada para sentimentos como preocupação, saudade e medo. Quando a carta do amor foi retirada, os alunos explicaram que "o amor pode ser aquele que sentimos pela família, pelos amigos, ou que também pode ser quando gostamos muito de outra pessoa, como na paixão, embora seja mais forte o amor do que a paixão".

Para finalizar o encontro, as turmas foram divididas em dois grupos. Um dos grupos deveria ficar inerte, como uma estátua, enquanto o outro representaria as emoções que fossem citadas pela estagiária. Ao final, o grupo que ficou imóvel (em estátua) relatou que é "sem graça" não ter sentimentos e que os sentimentos dão significado para o que acontecesse conosco.

\section{Segundo encontro: A alegria, os Monstrinhos e o que faz o outro feliz}

No segundo encontro foi discutido sobre a alegria. Os alunos foram questionados o que sabiam sobre este sentimento e as respostas foram dadas utilizando exemplos como: "é como quando ganhamos um presente e o nosso cérebro diz para nós ficarmos felizes". Esta fala foi

importante visto que recapitulou o que foi discutido no primeiro encontro. Em seguida, foi 
perguntado sobre "o que nos faz feliz". Novamente, os alunos deram exemplos: "ganhar um abraço", "brincar com o meu cachorro", "ficar com a família". Perguntou-se, então, se haviam outros sentimentos que poderiam nos trazer alegria. Alguns alunos achavam que não, enquanto outros citavam o amor, a paixão, a coragem e o carinho. Neste momento foi conversado sobre a importância de aceitar a si mesmo e não se comparar aos outros, pois desta forma seremos mais alegres com nós mesmos.

Por fim, questionou-se sobre de que forma a alegria é expressada e como é percebida nos outros. As respostas foram o sorriso e o pular (euforia). Foi questionado se não podemos perceber a alegria pelo jeito de andar. As crianças pensaram um pouco e falaram que, de fato, caminhamos "com o peito mais para fora", "de cabeça erguida", "com vontade", quando se está alegre. Então, para finalizar, foi perguntado se não é possível chorar quando alguém está alegre. Com espanto todos falaram que não, que choramos quando estamos tristes. No entanto, um aluno lembrou que podemos chorar de emoção ou podemos chorar, também, quando estamos muito alegres.

Neste mesmo encontro, os alunos foram convidados a ler a história do Marcelo e de seus monstrinhos: "Marcelo é uma criança que diz sentir um monte de coisas na barriga. Quando pergunta para sua mãe o que ele está sentindo ela lhe responde que deve ser fome ou vontade de ir ao banheiro" (CASARIN, 2016). Após esta leitura, foram questionados sobre o que poderiam ser as coisas na barriga de Marcelo e a resposta foi dita em voz única: “Germes!”. Então, foram perguntados se quando estão muito ansiosos pelo aniversário, ou com muito medo de apresentar um trabalho, ou se diante de situações como estas eles não sentiam "borboletas na barriga". As crianças pensaram um pouco e falaram que sim, que então os monstrinhos do Marcelo poderiam ser sentimentos. Assim a história seguiu: "Até que um dia, diante de uma situação muito alegre, o menino diz sentir coisas na barriga novamente, então a mãe explica que são sentimentos. Marcelo decide chamar esses sentimentos de monstrinhos" (CASARIN, 2016). Explicou-se que Marcelo utilizou o termo "monstrinhos" para dar nome aos sentimentos porque ainda não os conhece, e nós costumamos sentir medo daquilo que não conhecemos. No entanto, com o passar do tempo o menino vai conhecer os seus sentimentos e assim virar amigo dos seus monstrinhos.

Foi, então, lida a última parte da história: "Marcelo percebeu que quando algo muito bom acontece, o monstrinho da alegria aparece. Este monstrinho o deixa agitado, não pára de pular e sorri o tempo todo. Quando Marcelo fica alegre, ele percebe que seus pais também ficam alegres e ele sabe disso porque seus pais abrem um grande sorriso” (CASARIN, 2016). Desta forma, foi 
conversado com as crianças que, ao trazer alegria para as pessoas que gostamos, de certa forma nós também ficamos alegres, como os pais de Marcelo. Assim, foi realizado o "contrato da alegria" com as crianças. Explicou-se, novamente, que a palavra "contrato" significa se comprometer a fazer algo, e assim, neste contrato, eles deveriam refletir sobre o que faz eles alegres, o que faz seus pais alegres, sua professora e seus amigos. Ao final, cada um deveria assinar seu nome, comprometendo-se a praticar as atitudes e comportamentos dados como resposta na atividade.

Por fim, foi realizada uma brincadeira de "repórter-detetive". Cada aluno recebeu um papel colorido e deveriam encontrar o seu par (que estivesse com a mesma cor de papel). Ao encontrar a pessoa, deveriam perguntar o que faz o colega alegre e anotar no papel. Desta forma, eles poderiam conhecer mais sobre os colegas e, se possível, alegrar o colega. As respostas sobre o que os faz alegres foram "ganhar um abraço", "receber carinho do pai e da mãe”, "brincar com o irmão/irmã”, “comer picolé/sorvete", "jogar bola", "brincar com os amigos”, entre outras. No final do encontro as crianças foram solicitadas a fazer um trabalho com os pais, no qual deveriam confeccionar seu próprio monstrinho da alegria e entregar no próximo encontro.

\section{Terceiro encontro: os monstrinhos, a tristeza e o vento}

No terceiro encontro as crianças trouxeram o monstrinho confeccionado junto com os pais. Todos puderam mostrar seu monstrinho e conversar sobre como foi fazer o mesmo. Após isso, conversou-se sobre a tristeza. Foi perguntado como é expressado ou identificado este sentimento. Os alunos falaram que podemos identificá-lo "pelas lágrimas" ou porque "a boca fica virada para baixo". Explicou-se que também pode-se ver pelo jeito de andar, com os ombros e a cabeça baixos. Em seguida, questionou-se o que se pode fazer quando estamos tristes e as respostas foram "podemos assistir um filme”, "brincar", “jogar bola”. Neste momento foi comentado que é importante pensar em pessoas que podem nos escutar e nos ajudar, como nossos pais, amigos e professora, pois se estamos tristes é porque estamos com algum problema que talvez não consigamos resolver sozinhos, e estas pessoas vão nos ajudar a solucionar o problema. Neste momento, cada criança pode pensar com quem pode contar.

Então, continuou-se a história do Marcelo, iniciada no encontro anterior. "Certo dia, o

amigo de Marcelo não quis brincar com ele, e assim Marcelo descobriu outro monstrinho, o monstrinho da tristeza. Quando este monstrinho aparece, Marcelo fica com uma vontade sem fim de chorar e normalmente não quer conversar. O menino observou que seus ombros ficam caídos, 
sua cabeça fica baixa e sua boca fica igual a de um sapo" (CASARIN, 2016). Foi frisada a parte em que o Marcelo ficou triste porque o amigo não quis brincar com ele, e comentado que estas situações podem acontecer com qualquer um de nós. Foi questionado, então, como eles se sentiriam se isso acontecesse com eles. Todos falaram que ficariam "tristes", alguns com "raiva" e outros sentiriam-se "rejeitados". Então, as crianças foram questionadas sobre o que poderia ser feito diante desta situação: "chamar outro amigo para brincar", "pensar se não estamos fazendo algo para que o amigo não queira brincar" ou ainda "ficar sozinho e triste".

Por fim, os alunos foram convidados a pensar que o "Marcelo estava ali, e que seu amigo não quis brincar com ele. Então ele está sozinho no patio". Desta forma, foram questionados “o que fariam ao ver o Marcelo assim?" Uma aluna respondeu que "não faria nada, para não me meter", mas a grande maioria disse que convidaria o Marcelo para brincar. Após este momento de reflexão outras atividades foram realizadas. A primeira foi o "desenho passa-passa", no qual as crianças deveriam desenhar o monstrinho da tristeza e cada vez que ouvissem um apito, deveriam passar o desenho para o lado, e o colega tinha que continuar o desenho. O objetivo era refletir que a vida se parece com esta atividade, pois muitas vezes recebemos coisas que não esperamos, e ficamos tristes porque as coisas não vão sair do modo planejado. No entanto, com calma e paciência, as coisas vão entrando em ordem e, no final, podem-se ter resultados ainda melhores do que os planejados e são percebidos por meio do quanto aprende-se com este sentimento.

Para a atividade seguinte, foi mostrado um desenho de um dia com muito vento. Então, cada um devia fazer o seu desenho do vento. Ao final, refletiu-se sobre a relação entre o vento e a tristeza sendo que a última é como o primeiro, ela vem, e depois passa.

\section{Quarto encontro: o medo, a raiva e as possibilidades de manejo}

No quarto encontro foram trabalhados dois sentimentos: o medo e a raiva. Começou-se pela raiva e discutiu-se sobre as formas de expressar ou identificar este sentimento. Em seguida continuou-se com a história do Marcelo: "Quando alguém tinha algum comportamento que Marcelo não gostava, ele sentia vivo dentro da sua barriga um monstrinho agitado, ele percebeu que quando estava raivoso ficava com muita vontade de gritar e de mostrar pra todo mundo o tamanho da sua força. Quando as pessoas ficam com raiva, elas geralmente mordem os lábios $e$ fazem uma cara de dar medo" (CASARIN, 2016). Foram discutidos os motivos da raiva de Marcelo, e ensinado algo que o menino não sabia: "tudo aquilo que os outros fazem ou pensam, 
seus comportamentos, atitudes, suas palavras, seus erros ou suas ideias, são responsabilidade apenas deles mesmos, nós não podemos controlar, só podemos controlar o que é nosso". Então foilhes dado um exemplo: "Quando um colega me empurra na hora da fila, ele é o único que pode se controlar e impedir que tenha esse comportamento. Assim, se eu não posso controlar aquilo que ele faz, eu devo controlar o que eu vou fazer diante deste acontecimento." Concomitante, foi-lhes dado três sugestões de solução: (1) a primeira seria a resposta agressiva ou "ruim": empurrar o colega de volta. Foi-lhes explicado que esta não é a solução adequada, pois não soluciona o problema, só torna ele maior. A (2) segunda seria a resposta passiva, que seria uma resposta "mais ou menos", que é não fazer nada. Explicou-se que, “aparentemente” seria bom não fazer nada, já que não causa maiores problemas. Neste momento, as crianças forma convidadas a imaginar que a estagiária tinha uma mochila nas costas, e que cada atitude ou comportamento ruim que tivessem para com ela, seria guardado nesta mochila. Por exemplo, a estagiária guardaria na mochila tudo aquilo que é responsabilidade dos outros, que ela não pode controlar como, por exemplo, alguém a "xinga" ou a empurra. Tudo vai para a mochila até que ela pesa e, desta forma, quem carrega a mochila poderá entrar em uma tristeza muito grande, ou irá explodir toda a sua raiva e se voltar a pessoas que não têm nada a ver com o que aconteceu.

Desta forma, a estagiária pode explicar que "não fazer nada" não é tão legal assim, pois pode-se acabar guardando coisas ruins, que na verdade são dos outros. Por fim, foi explicado o que seria adequado fazer diante da situação (3) resposta assertiva ou "boa". Foi sugerido, como alternativa, respirar fundo três vezes para acalmar o "monstrinho da raiva", e então conversar com o colega e explicar que não gostou do que ele fez, que ficou muito chateado. Além de pedir que ele não repita este comportamento. Desta forma, evita-se guardar coisas ruins dentro de si e impedese que o comportamento aconteça novamente.

Após isso, continuou-se com a história de Marcelo, sobre o medo: " $O$ medo é outro monstrinho que Marcelo conhece bem, pois quando este monstrinho aparece, Marcelo começa a pensar em tudo de ruim que pode acontecer. Ele reparou que, quando as pessoas ficam com medo, elas deixam de tentar e acabam não aprendendo coisas novas. As pessoas com medo ficam paralisadas, iguais estátuas” (CASARIN, 2016). Foi explicado que o monstrinho do medo se alimenta destes pensamentos ruins. Quanto mais pensarmos no pior, maior o monstrinho fica e mais difícil fica de enfrentar o medo. Foi dado como exemplo o medo de falar em público. “Quando temos que apresentar uma peça de teatro, ou jogar uma partida de futebol começamos a pensar no 
pior: "vou esquecer tudo", "não vou conseguir", vou errar”. Após isto, a estagiária conversou com as crianças que, agindo desta forma, são alimentados os "nossos monstrinhos", que vão tornando o medo maior e mais difícil de enfrentar. Desta forma, propôs formas de solucionar o problema, conversando junto com as crianças. A primeira solução, considerada "ruim", é pensar em tudo de ruim que poderia acontecer e deixar de ir por conta do medo. A solução seria ruim, pois torna o medo maior e faz com que não solucionemos o problema. A segunda solução, que estaria entre a solução "ruim" e a "boa", seria evitar essas situações (não participar da peça de teatro; não ir no jogo de futebol ou não aceitar convites para dar aula). É considerada uma solução mediana, pois refere-se à evitação do enfrentamento de situações em que eu precise lidar com esse medo. Por fim, melhor alteria seria respirar fundo para acalmar o monstrinho do medo e pensar em coisas boas como, por exemplo, “eu consigo", "eu me preparei”, para afastar os pensamentos ruins.

Após as explicações, a turma foi dividida em dois grupos em forma de filas. As duas primeiras filas teriam que pensar em uma situação que os deixasse com raiva. Então, escreveriam a situação, fariam um desenho e no final dariam a solução boa (assertiva) para a situação. As outras duas filas fizeram o mesmo sobre o medo. Após, foi discutido sobre as soluções que os grupos pensaram e finalizado o quarto encontro.

\section{Quinto encontro: amor próprio}

O quinto encontro foi voltado para o amor próprio. Para a primeira atividade os alunos receberam uma folha com dois personagens, um menino e uma menina segurando vários balões, nos quais estava escrito nos balões azuis "eu sou...", nos balões rosa “eu gosto..." e nos amarelos "eu sinto...". Estes balões representavam suas características pessoais. Para os balões azuis a estagiária expos diversas palavras no quadro como: alegre, amigável, bondoso, calmo, carinhoso, confiável, corajoso, curioso, educado, esperto, generoso, inteligente, organizado, otimista, ousado, sensível, simpático, solidário.

Após isso, cada aluno deveria escolher as seis palavras para descrever a si mesmo, podendo utilizar outras que não estivessem na lista. Nos balões amarelos, foi sugerido que pensassem nos cinco sentimentos que mais sentiram no último mês. Por fim, nos balões rosa, deveriam pensar nas coisas que mais gostam de fazer. Ao lado dos bonecos, os alunos deveriam escrever as três características físicas que mais gostavam em si. 
Para introduzir a segunda atividade, foi contado aos alunos que pensar nessas características é muito importante para que o amor que sentimos por nós mesmos se fortaleça. Mas há outro fator importante, que é a nossa história, pois ela também faz parte de quem nós somos. Então foi-lhes contada a história "O coração mais bonito": Gustavo estava para ganhar o concurso do coração mais bonito. Ele tinha um lindo coração, sem nenhuma ruga, sem nenhum estrago. Até que apareceu o senhor Geraldo e disse que seu coração era o mais bonito. As crianças comentaram: "Como seu coração é o mais bonito, com tantas marcas?". O bom velhinho, então explicou que era isso mesmo que tornava o seu coração bonito. Aquelas marcas representavam tudo o que ele viveu, as pessoas que ele amou e que o amaram. Finalmente todos concordaram, o coração de Gustavo, apesar de lisinho, não tinha a experiência do coração de Geraldo”. Cada aluno recebeu um coração no qual deveria colocar as suas "marquinhas", considerando as pessoas que eles amam e os acontecimentos mais marcantes que ocorreram ao longo de suas vidas. A finalização do quinto encontro deu-se por meio da discussão das atividades realizadas.

\section{Sexto encontro: $O$ amor dirigido aos outros}

No sexto encontro foi trabalhado o amor dirigido aos outros, aquele que os outros sentem por nós. Pensando nisso, foi proposta a reflexão sobre o amor como um sentimento complexo. Para tanto, foi comparado com a alegria, a qual pode ser percebida por meio de um sorriso, ou a tristeza, percebida pelas lágrimas ou da "boca virada para baixo", como citado pelas crianças em encontros anteriores. Desta forma, a estagiária de psicologia discutiu com as crianças sobre o amor, percebendo que a expressão facial nem sempre demonstra de maneira explícita o sentimento. Assim, deve-se levar em consideração as atitudes como, por exemplo, o fazer carinho, dar abraço, beijo e por meio de falas como o "eu te amo". Além disso, o amor pode ser expresso por meio da preocupação quando ficamos doentes.

Após a discussão, as crianças receberam uma folha com o desenho de uma árvore chamada “Árvore do amor”. Em cada folha da árvore os alunos deveriam colocar o nome de uma pessoa que amam e que os faz se sentirem amados. O objetivo da árvore é que eles pensassem não só em pessoas que amam, mas também em pessoas que os ajudariam ou, simplesmente, os escutariam quando se sentissem tristes, com medo, ou com raiva, ou seja, criar a rede de apoio.

$\mathrm{Na}$ atividade seguinte, eles deveriam escolher uma das pessoas da árvore e escrever uma cartinha para a pessoa, agradecendo pelos momentos de ajuda e/ou ensinamentos, ressaltando 
aquilo que admiravam nele e o quanto a mesma é importante em suas vidas. Algumas crianças encontraram dificuldades para escrever a carta, pois não sabiam o que escrever. Desta forma, a estagiária teve que ajudar alguns alunos.

Para finalizar a atividade, foi-lhes entregue um coração pequeno, no qual deveriam escrever o que desejavam que o colega à sua direita tivesse dentro de seu coração. Em seguida, eles viraram o coração e escreveram o que queriam dentro do seu coração. O objetivo da atividade era refletir sobre o que desejamos aos outros e aquilo que queremos para nós.

\section{Sétimo encontro: revisão dos encontros anteriores e a finalização das atividades}

No ultimo encontro foram revisadas as atividades e reflexões dos encontros anteriores, relembrando as formas de identificar e o que fazer com cada sentimento. Para isto, os alunos fizeram duas atividades. Na primeira, cada aluno recebeu um termômetro com carinhas representando o amor, a alegria, a raiva, o medo e a tristeza. As crianças puderam recortar e enfeitar do modo que preferiram. Após isso, foi construído um varal na sala de aula com todos os termômetros. Foi combinado, previamente com a professora de cada turma, que as mesmas deveriam dar um tempo no inicio e/ou no final da aula, para que eles elegessem o sentimento mais forte naquele dia e colocassem a intensidade do sentimento. Com isso, cada aluno, ao ver o termômetro do colega, poderia ajudá-lo com seu sentimento, de acordo com o que foi aprendido. Para a atividade seguinte, os alunos receberam uma folha de revisão, com algumas questões relacionadas à identificação dos sentimentos. Com o objetivo de finalizar os encontros, cada aluno recebeu um cartão de agradecimento.

\section{Discussão}

A partir da compreensão dos sentimentos básicos, podemos apresentar compaixão pelos outros e ter sensibilidade por suas dificuldades (VISCOTT, 1982). Os sentimentos básicos são o medo, a raiva, o amor, a alegria, a tristeza e o nojo (CAMINHA; CAMINHA, 2011). Por este motivo, o projeto desenvolvido abarcou estes sentimentos supracitados. Segundo os autores, o medo tem como função principal preservar os aspectos físicos e psicológicos do individuo. É, além disso, um sentimento importante para desenvolver a capacidade de adaptação. Por sua vez, a raiva é considerada um sentimento mais negativo, já que pode produzir danos se não for expresso de forma assertividade. $\mathrm{O}$ mesmo se assemelha com a tristeza, pois ambos são sentimentos negativos 
que podem causar dano, tanto no ambiente, quanto nos indivíduos que nele habitam. A tristeza surge diante de situações de fracasso ou separação, mas pode ser benéfica quando permitir que o sujeito reflita e repare, modifique a realidade para melhorá-la. Já a alegria surge na presença de acontecimentos desejados, pode ser individual ou coletiva, este sentimento traz o benefício de reforçar vínculos. Por fim, o amor, segundo os autores, tem a função de cuidado e manutenção de vínculos.

Tendo em vista a possibilidade de impedir o surgimento de danos psicológicos decorrentes das situações cotidianas, Caminha e Caminha (2011) atentam para a necessidade de se investir em intervenções precoces. Complementando este pensamento, Froner (2008) lembra sobre a importância de promover o crescimento emocional na infância, pois ao investir nessas intervenções é favorecida a formação de um suporte adequado que oportuniza o aprendizado acerca de como monitorar os sentimentos e identificar as necessidades próprias ou dos demais. O mesmo autor ainda menciona que o comportamento é conduzido pelos sentimentos. Esta relação entre os sentimentos e o comportamento, favorece a adaptação do sujeito e produz mudanças sociais e pessoais (CAMINHA; CAMINHA, 2011; FONSECA, 2016).

Para Viscott (1982), os sentimentos são formas de reagir aos acontecimentos do dia-a-dia, podendo definir a forma como percebemos o mundo e tudo o que acontece nele. Assim, os sentimentos são fatores que influenciam as reações frente aos acontecimentos presentes, passados e futuros. A afirmação do autor contribui com a discussão realizada no primeiro encontro, considerando que o nosso comportamento age de acordo com o sentimento que é despertado pela situação. Desta forma, torna-se praticamente impossível compreender a realidade sem considerarmos os sentimentos gerados por ela nos indivíduos que nela vivem.

De forma a ressaltar a necessidade de discutirmos os comportamentos gerados pelos sentimentos, Viscott (1982) afirma que quando evitamos um sentimento, aumentamos seus efeitos negativos e dificultamos o enfrentamento dele, podendo colaborar, segundo Froner (2008), para uma série de prejuízos nos relacionamentos futuros. Desta forma, Goleman (1995) atenta para a existência de outras formas para resolver os conflitos além da passividade ou agressão. No encontro em que foram trabalhados os sentimentos medo e raiva, os alunos refletiram sobre suas reações frente às situações que despertaram tais sentimentos, pensando em formas assertivas para resolvêlos. 
Aprender sobre os sentimentos e as formas de reação que apresentamos ao experimentá-los é também, aprender sobre nós mesmos. De fato, Viscott (1982) indica que os sentimentos refletem nossa história, nosso desenvolvimento, nosso passado, presente e potencial futuro. A competência em regular os sentimentos é essencial para o conhecimento emocional e para a autocompreensão. Ainda, Goleman (1995) afirma que quanto maior a consciência sobre nossas próprias emoções, mais facilmente entenderemos o sentimento dos outros.

O autor supracitado chama a atenção para a importância de desenvolvermos a empatia, qualidade que nos permite ter o entendimento dos sentimentos dos outros. Por conseguinte, é imprescindível o entendimento dos canais não verbais para a identificação dos sentimentos em si e nos outros, considerando como constituintes desses canais o tom da voz, gestos, expressão facial, entre outros. Considerando as contribuições do autor, o projeto "Meu mundo interior sentimentos" reforçou as expressões faciais e corporais apresentadas por permitir às crianças a experimentação de cada um dos sentimentos trabalhados. Além disso, o projeto possibilitou a identificação e o entendimento dos sentimentos dos outros, podendo, desta forma, favorer a expressão da empatia. Ainda, quase todas as atividades envolveram os colegas (grupos ou subgrupos, pais e professores), indicando a importância do outro e de seus sentimentos. A participação e o envolvimento tanto das professoras, como da turma, são aspectos essenciais, pois contribuem para o reconhecimento do trabalho com sentimentos, pelas professoras. Ainda, a participação dos pais foi um importante aspecto, já que os alunos demonstraram a alegria em ter construído, junto com os pais, o monstrinho. Para os pais, foi uma atividade importante, indicando os aspectos positivos de seu envolvimento com as atividades escolares dos filhos.

Outro aspecto importante refere-se ao fato do trabalho ter sido realizado em grupo com as crianças, o qual permite o compartilhamento de comportamentos e sentimentos, além da possibilidade de trocas (DE OLIVEIRA; DE MENEZES; BRITO; PINTO, 2018). Anterior ao projeto, várias observações foram realizadas, com o intuito de identificar demandas das turmas de alunos para o posterior desenvolvimento da intervenção. $O$ trabalho da psicologia escolar/educacional deve sempre vislumbrar as reais demandas de cada grupo ou subgrupo, sendo importante escutar a equipe diretiva, os alunos, pais e professores com o intuito de pensar em intervenções adequadas para cada contexto e de acordo com as necessidades de cada grupo. 


\section{Considerações finais}

O relato descreve uma experiência de estágio básico curricular da graduação em psicologia o qual foi realizado em uma escola privada de ensino fundamental de uma cidade do norte do Rio Grande do Sul. Após observações da demanda, foi construído o projeto de intervenção nomeado "Meu mundo interior - Sentimentos", o qual foi aplicado em três turmas do segundo ano do ensino fundamental. O projeto teve como objetivo possibilitar um espaço de reflexão sobre os sentimentos e refletir sobre quais as melhores formas de expressá-los, incluindo o "perceber", o "nomear", o “verbalizar" e o “expressar" e o "comportamento" (RODRIGUES, 2015; 2016).

Após a análise dos sete encontros realizados com três turmas de segundo ano do ensino fundamental da escola, torna-se clara a importância de se trabalhar no ambiente escolar, o qual apresenta muitas demandas, tanto por parte dos alunos, quanto dos pais, professores e demais funcionários. Além do relato apresentado, em si, a experiência de estágio oportunizou a ampliação da visão do trabalho do profissional psicólogo dentro da área escolar, para além de um ouvinte e mediador, mas como educador de processos cognitivos e comportamentais, atingindo, por consequência o âmbito das relações sociais.

A participação dos pais e/ou cuidadores, bem como dos professores, é imprescindível, já que as crianças ainda são dependentes desses adultos e passam muitas horas de seu dia com eles. A participação pode auxiliar pais/cuidadores e professores a compreender certos comportamentos das crianças, auxiliando-as na identificação e no manejo mais adequado.

A continuidade do projeto é necessário, já que algumas habilidades podem ser desenvolvidas e outras podem ser extintas com o tempo. Outro aspecto importante refere-se a avaliação de habilidades socioemocionais antes e após a intervenção, podendo indicar se, de fato, mudanças ocorreram e foram substantivas, pois a avaliação foi realizada apenas por meio da observação das crianças que participaram dos grupos e por meio de conversas formais e informais com professores e pais.

Embora se tenha ciência a respeito das limitações de tal intervenção, na escola em que foi realizado o estágio, não havia espaço para trabalhar com os professores e pais, sendo que a proposta da escola, desde o início, foi de trabalhar com grupos de alunos. Embora saibamos sobre a importância de uma análise maior, que envolva todos (pais, professores, funcionários e gestores), no momento da realização do estágio, a intervenção descrita foi a proposta possível. 


\title{
"MY INSIDE WORLD - FEELINGS": REPORT OF INTERNSHIP EXPERIENCE IN SCHOOL/EDUCATIONAL PSYCHOLOGY
}

\begin{abstract}
Emotional education can be one of the operational areas of school/educational psychology. The work consists in preventing conflicts, which assists children to properly identify and express what they feel. This article shows an internship research, made in a private Elementary School located in a city in the North of Rio Grande do Sul. After a careful study on demand, an intervention project called "My inside world - feelings" was created, which was then put in practice with three groups of second grade students. The project was run by the intern and the teacher in charge of each class, in a total of seven meetings of about one hour. In which the children were able to comprehend, speak and express their feelings.
\end{abstract}

Keywords: emotional education; children; school psychology.

\section{"MI MUNDO INTERIOR - SENTIMIENTOS": RELATO DE EXPERIENCIA DE PRÁCTICAS EN PSICOLOGÍA ESCOLAR/EDUCATIVA}

\begin{abstract}
Resumen
La educación emocional puede ser una de las formas de actuación de la psicología escolar/educativa. Es una posibilidad para la prevención de conflictos que ayuda a los niños a reconocer y a manifestar, de manera adecuada, sus sentimientos. En este artículo se describe la experiencia de prácticas en el nivel básico que se realizó en una escuela primaria privada de una ciudad del norte del estado de Rio Grande del Sur. Después de observaciones de la demanda, se desarrolló el proyecto de intervención nombrado "Mi mundo interior Sentimientos", que fue aplicado a tres grupos del segundo año de la enseñanza primaria. El mismo fue realizado por la alumna en prácticas junto a la profesora de cada grupo en un total de siete encuentros de aproximadamente una hora de duración cada uno. Los niños pudieron reconocer, verbalizar y expresar diversos sentimientos.
\end{abstract}

Palabras Clave: educación emocional; niños; psicología escolar.

\section{REFERÊNCIAS}

ANDRADA, E. G. C. (2005). Novos Paradigmas na prática do psicólogo escolar. Psicologia Reflexão e Crítica, 18(2),196-199.

CAMINHA, R. M., CAMINHA M. G. (2011). Baralho das emoções: Acessando a criança no trabalho clínico ( $4^{\mathrm{a}}$ edição). Porto Alegre: Sinopsys Editora.

CASARIN, T. (2016). Tenho monstros na barriga (2a edição). Fundação Leamann.

DE OLIVEIRA, P., DE MENEZES, BRITO, S. S., PINTO, P. S. P. Menezes, M. B., Brito, S. (2018). Psicoeducação das emoções e habilidades sociais: uma proposta de promoção e prevenção de saúde mental para adolescentes. Seminário Estudantil de Produção

Acadêmica, 17. 
DIAS, A. C. G., PATIAS, N. D., ABAID, J. L. W. (2014). Psicologia escolar e possibilidades na atuação do psicólogo: Algumas reflexões. Revista Quadrimestral da Associação Brasileira de Psicologia Escolar e Educacional, 18(1), 105-111.

FONSECA, V. (2016). Importância das emoções na aprendizagem: uma abordagem neuropsicopedagógica. Revista Psicopedagógica, 33(102), 365-384.

FRONER, C. C. M. (2008). A preparação emocional na infância: Família X Escola (1 a edição). Santa Maria: ITPOH.

GOLEMAN, D. (1995). Inteligência emocional. Rio de Janeiro: Objetiva.

PATIAS, N. D., ABAID, J. L. W. (2014). O que pode fazer um estagiário de psicologia na escola? Problematizando prática e formação profissional. Educação, 39(1), 187-200.

RODRIGUES, M. (2015). Educação emocional positiva. Novo Hamburgo: Sinopsys Editora.

RODRIGUES, M. (2016). Resolução de problemas: Guia prático. Disponível em:

www.ebook.educacaoemocionalpositiva.com.br

VISCOTT, D. (1982). A linguagem dos sentimentos (18 a edição). São Paulo: Summus.

Data de recebimento: 20/12/2017

Data de aceite: 17/09/2019

Sobre as autoras:

Fernanda Brugnera é psicóloga (IMED). Endereço Eletrônico: fer_brugnera@ hotmail.com

Naiana Dapieve Patias é doutora em Psicologia (UFRGS) e docente no Departamento de Psicologia da Universidade Federal de Santa Maria (UFSM). Endereço Eletrônico: naipatias@hotmail.com 